\title{
Adaptation and validation of the psychosocial values questionnaire to the context of Brazilian and Portuguese teenagers
}

\author{
Samuel Lins ${ }^{1 *}$, Gabrielle Poeschl${ }^{2}$, Tiago Jessé Souza de Lima ${ }^{3}$, Luana Elayne Cunha de Souza ${ }^{3}$ \\ and Cícero Roberto Pereira ${ }^{4}$
}

\begin{abstract}
The aim of this work was to adapt and validate the Psychosocial Values Questionnaire (PVQ-24) for application to Portuguese and Brazilian adolescents and to test the content, structure and compatibility hypotheses of the societal approach to values. A total of 730 adolescents participated in the study, 482 Brazilian (213 boys and 269 girls) with average age of 15 years $(S D=1.1)$ and 238 Portuguese (117 boys and 121 girls) with average age of 15.4 years $(S D=1.8)$. In both samples, the PVQ-24 showed satisfactory internal consistency, and the proposed factor structure was confirmed (four systems: materialistic, religious, hedonistic, and post-materialist). The post-materialist system was organized into three subsystems: social well-being, individual well-being and occupational well-being. In both samples, confirmatory factor analysis and multidimensional scaling supported the hypotheses regarding content (four systems and three subsystems), structure (two dimensions) and compatibility (positive correlations between systems).
\end{abstract}

Keywords: Values, Validity, Content, Structure, Adolescents

\section{Background}

Studies about human values have gained prominence due to the important role this construct plays in the human behavior (Rokeach 1973), leading to the development of several theories on values, like those proposed by Rokeach (1973), Inglehart (1991) and Schwartz (1992). These theories are based on a dichotomous view of the nature of human values, where values are explained as having an individual nature or social nature. In turn, the societal approach to human values (Pereira et al. 2005) seeks to integrate these explanations, taking into account the need to integrate multiple levels of explanation of psychosocial phenomena in social psychology (Doise 1982). In this sense, this work aimed to test in a cross-cultural context (Brazil and Portugal) the hypotheses of content, structure and compatibility of this approach, as well as to adapt and test the construct validity of the Psychosocial Values

\footnotetext{
* Correspondence: samuellins@puc-rio.br

${ }^{1}$ Pontifical Catholic University of Rio de Janeiro, Rio de Janeiro, Brazil Full list of author information is available at the end of the article
}

Questionnaire (PVQ-24), the measure used in the societal approach, to study the values in adolescents.

Adolescence is a transition period usually characterized by significant changes in the development of various aspects related with life in society (Blakemore and Mills 2014). Typical changes in this period reflect patterns and behaviors that affect both the way teens experience the present and their future behavior (Santos and Fernandes 2011), which makes the analysis of human values particularly relevant in this period of life. In this context, having a measure that adequately assesses human values can make an important contribution to conducting research that takes in account the impact of social values in the various fields of adolescents' everyday life.

\section{Human values in social psychology}

In social psychology, the explanations about the nature of human values are mostly at the intra-personal level (Torres et al. 2001). In this sense, the sources of values are individual needs (Rokeach 1973), which are distributed hierarchically and organize the beliefs of individuals in a 
value system (Pereira et al. 2005). The models proposed by Rokeach (1973), Schwartz (1992) and Gouveia et al. (2014) are representative of this perspective. Another perspective understands values as abstract ideas, implicitly or explicitly shared, about what is right, good and desirable in a society or culture (Williams 1979). In this perspective, we can cite models that explain values at the cultural level, such as those proposed by Schwartz (2006), Inglehart (1977, 1989) and Hofstede (1980).

Rokeach (1973) and Schwartz (1992) proposed a conception of the nature of values as having intra-personal character, which the source of values having a motivational nature based on the biological needs of group survival and coordinated social interaction. For Rokeach (1973), values are beliefs concerning desirable modes of conduct (instrumental values) or desirable end-states of existence (terminal values). With some modifications, Schwartz (1992) adopted the concept of values employed by Rokeach (1973) and used his method as a basis to measure values. Schwartz and Bilsky (1987) articulated the conception of social desirability of values, as proposed by Kluckhohn (1951), with the main characteristics of Rokeach's (1973) theory. According to Schwartz (1992), when we think about our values, we think about what is important in our lives. Schwartz (1992) defined values as desirable and transcendent goals, hierarchically ordered by importance, that serve as principles in the life of a person or a social entity.

On the other hand, Inglehart (1989), from a sociological perspective, proposed that values represent cultural changes in the history of societies, that is, human values have a cultural nature since they are markers of cultural changes. Inglehart (1989) argued that the change from the feudal to the capitalist production system favored the emergence of materialist values, and that the economic stability of some post-industrial societies facilitated the emergence of post-materialist values. In this sense, the societies that have not solved basic social problems give more importance to materialistic goals, while societies that have reached a certain degree of resolution of these problems endorse post-materialistic goals. Studies conducted in different cultures (Bean and Papadakis 1994; Kidd and Lee 1997; Pereira and Camino 1999) have shown that materialist values are associated with concerns about economic stability and post-materialist values are associated with social and individual well-being and professional achievement.

According to Estramiana et al. (2014), these models are based on two assumptions about the nature of values, which also permeate other concepts studied in social psychology: the nature of values is individual, when they serve individual needs (Schwartz 1992), or the nature of values is social, when they emerge from cultural changes (Inglehart 1989). In an effort to overcome this opposition, a model was proposed seeking to articulate the individual and cultural conceptions of the human values through a societal approach.

\section{Societal approach to values}

Based on the previous problems, and taking into account the need for articulation between the levels of explanation of psychosocial phenomena in social psychology (Doise 1982), the societal approach to values has been proposed. This approach aims to articulate into an integrative model the psychological perspective of motivational types, proposed by Schwartz (1992), with the sociological perspective of materialist and post-materialist values, proposed by Inglehart (1989).

This model assumes that the genesis of values is in the social production of meaning. Values are understood as a phenomenon of social order linked to a psychological phenomenon, as they are seen as knowledge elements widely shared in society, enabling individuals to understand and be understood in the context of social relations (Costa 2000; Maio et. al 2001). Because values are social productions of meaning, they need a set of social conditions for their emergence (Deschamps and Devos 1993; Pereira et al. 2005). The model assumes that these conditions are the ideological struggles waged by social groups in search of power (Pereira and Camino 1999), which are part of the social construction of reality (Berger and Luckmann 1973). In this sense, the source of values lies in ideological identities that guide social groups (Costa 2000).

The emergence of values in society is not conditioned to the fact they cognitively represent individual goals, as advocated by Schwartz (1992), or collective needs, as proposed by Inglehart (1994). In fact, values emerge to represent the various ideological tendencies with which social groups are identified (Pereira et al. 2004a). In accordance with these assumptions, values are defined as knowledge structures socially produced that (a) synthesize the elements of a widely shared symbolic system, (b) express the ideological conflicts that form this system, (c) guide selection of alternative behavior and (d) reflect the socio-cultural context and individual social identities (Costa 2000; Estramiana et al. 2014; Fernandes et al. 2007).

\section{Content and structure of values}

The societal approach proposes that values represent the various ideological tendencies with which social groups are identified. These tendencies are organized into four systems with different contents: materialist, post-materialist, religious and hedonistic (Pereira et al. 2004a, b, c, 2005).

The materialist system represents the ideology of accumulation of wealth and social status (Inglehart 1994). Individuals or groups guided by such values are focused on getting material resources and accumulating power while 
they cherish authority. The values that represent this system are wealth, authority, status and profit.

The post-materialist system represents the ideologies that are emphasizing more abstract ideas instead of material goals, like social well-being, self-realization and knowledge (Inglehart 1977). This system contains three subsystems: social well-being, personal well-being and professional well-being (Pereira et al. 2004a, b, c, 2005). Social well-being represents the identification with the welfare of society and is associated with broader issues like human rights and citizenship. This subsystem is represented by the values of social justice, freedom, equality and fraternity. Individual well-being involves identification with more abstract personal achievements and subjective well-being, being constituted by the values of joy, love, comfort and self-fulfillment. Professional well-being entails the ideologies of self-realization in professional life, demonstrating responsibility and competence. This subsystem consists of values like professional achievement, hard work, responsibility and competence (Pereira et al. 2004a, b, c, 2005).

The religious system represents the ideology of obedience to religious rules, beliefs and norms of behavior (Schwartz 1992). In this sense, obedience to authority is important. This system covers the values of obedience to God's laws, religion, salvation and fear of God. Finally, the hedonistic system emphasizes the pursuit of pleasure, excitement in life, and appreciation of sexuality (Schwartz 1992). The values that represent this system are pleasure, excitement, sexuality and sensuality (Pereira et al. 2004a, b, c, 2005).

According to the societal approach, these four systems are organized in two dimensions. The first dimension comprehends the materialist and post-materialist systems (Inglehart 1977; Pereira et al. 2005). The second dimension opposes the religious and hedonism system. In fact, the religious and hedonistic systems can represent opposite interests (Schwartz 1996; Pereira et al 2005). Opposition is also likely between the materialist and post-materialist systems, since the values that form these systems emerged in different socioeconomic contexts (Inglehart 1977).

However, this approach proposes positive correlations between the different value systems, indicating that values are not structured based in conflict relationships, as stated by Schwartz et al. (2012), but in their possible compatibilities (Gouveia et al. 2014; Pereira et al. 2004a, b, c; Pereira et al. 2005). This pattern of positive relations between the value systems occurs because values have little to do with needs, since they are primarily related to ideas about how society should be organized (Deschamps and Devos 1993). Furthermore, Pereira et al. (2001) argue that a conception where value structures are based on conflicting relations (Schwartz et al. 2012) contradicts the social desirability present in these values.
Therefore, the societal approach content hypothesis proposes the existence of four value systems with different contents, named hedonism, religion, materialism and postmaterialism. The latter system also includes three correlated but distinct contents, represented by the subsystems of social well-being, individual well-being, and professional well-being. The structure hypothesis of the societal approach postulates the existence of two dimensions, with the first dimension including the materialist and postmaterialist systems and the second the religious and hedonistic systems. Furthermore, the societal approach proposes that these systems are organized in terms of their compatibilities because value systems are positively correlated with each other (Pereira et al. 2001).

In the following section, we present empirical evidence of the validity of the societal approach to values.

\section{Empirical evidence}

Based on the societal approach to values, the Psychosocial Values Questionnaire was developed (PVQ; Pereira et al. 1997; Torres 1992) to measure the value systems of social groups. The current version of the instrument consists of 24 items equally distributed among the value systems and subsystems proposed by the theory (Pereira et al. 2004a, b, c). This instrument has been widely used in several studies and has accumulated favorable empirical evidence of construct validity and reliability, confirming the hypothesis of the societal approach to values (Fernandes et al. 2007; Lins et al. 2014; Pereira et al. 2004a, b, c; Pereira et al. 2004c).

Pereira et al. (2004a, b, c) tested the construct validity of the PVQ-24 through confirmatory factor analysis in a sample of college students. The results support the adequacy of the items used to measure the four systems, with factor loadings ranging from .31 to .75 , supporting the content hypothesis. In addition, all systems showed Cronbach alphas above .70 and positive and significant correlations with each other, ranging between .09 and $.76(p<.05)$. These results reveal psychometric evidence of validity and accuracy of the PVQ-24. Internal consistency scores are above those frequently reported for other models in the literature. Commonly constructs, like values, that have low intersubject variability in responses tend to have low internal consistency (Rodriguez and Maeda 2006). The positive correlations observed also corroborate the claim that the systems are positively correlated with each other, indicating that the values are structured not based on relations of conflict, but on their possible compatibilities (Pereira et al. 2005).

Pereira et al. (2005) also tested the structure proposed by the societal approach using multidimensional scaling analysis. The results showed that the four systems emerge in separate areas and are organized in two dimensions: materialist-post-materialist and hedonist-religious. This 
study also provides evidence of convergent validity between the systems of the societal approach and the second order motivational types of Schwartz (1992). They observed correlations between materialism and self-promotion $(r=.49 ; p<.001)$, hedonism and openness to change $(r=.55 ; p<.001)$, religious and conservation $(r=.51$; $p<.001)$, and between post-materialism and selftranscendence $(r=.63, p<.001)$. These correlations support the approximation proposed by Pereira et al. (2001) between the societal approach to values and Schwartz's value theory (Pereira et al. 2005).

Other studies have also shown the relevance of using the PVQ-24 to understand various social behaviors, showing evidence of predictive validity for the societal approach to values. For example, Pereira et al. (2004a, b, c) evaluated the relationship between the value systems and attitudes toward democracy and found that adherence to the materialist system predicted a negative attitude toward democracy, while adherence to the post-materialist system contributed to a positive attitude. Fernandes et al. (2007) tested the relationship between values and social dominance orientation (SDO). They observed that the SDO was directly associated with materialist values and inversely associated with post-materialist values.

Pereira et al. (2004b), in a study about the role of values in people's involvement with human rights, found that post-materialist values were positively related with abstract involvement, whereas adherence to religious values implies more involvement in concrete efforts to promote human rights. In addition, adherence to materialist values was found to lead to a more positive evaluation of the government's involvement in human rights, while the post-materialist values contributed to a more critical evaluation of the government's role in promoting human rights. Barros et al. (2009), in a study testing the relationship between authoritarianism and values, observed that religious values were related to decrease in tolerance, while adherence to hedonist values was related to an increase in tolerance and reduction of authoritarianism. Furthermore, adherence to materialist values was related with higher levels of authoritarianism. Lins et al. (2014), in a study about the role of values in racial prejudice, found that adherence to hedonist and materialist values predicted the expression of prejudice against blacks. On the other hand, adherence to social justice values predicted the non-expression of prejudice.

In summary, studies conducted with the PVQ-24 show psychometric evidence of its construct validity in assessing the four proposed value systems of the societal approach to values. The internal consistency of this measure is high, especially when compared with other measures of values based on other theories. Research conducted with the PVQ-24 provides empirical evidence of the content and structure hypotheses of the societal approach to values.
However, the studies of the PVQ-24 have mainly been conducted with samples of Brazilian university students, so there is a lack of studies with different samples and in different countries. In this sense, the study reported here aimed to adapt and test the construct validity and reliability of the PVQ-24 in a sample of Brazilian and Portuguese teenagers and test the cross-cultural validity of the content and structure hypotheses of the societal approach to values.

\section{Method \\ Participants}

The participants were 730 adolescents, 482 students from Brazil (213 boys and 269 girls), aged between 12 and 18 years $(M=15$ years; $S D=1.10)$, and 238 pupils from Portugal (117 boys and 121 girls), aged between 13 and 18 years $(M=15.40$ years; $S D=1.80)$.

\section{Instruments}

The Psychosocial Values Questionnaire - PVQ-24 (Pereira et al. 2004a) was part of a more extensive instrument about the social representations of buying habits. In the part of the instrument which is analyzed here, students were asked to rate the importance of each of the 24 values (e.g., authority, pleasure, obedience, competence) on a 7-point scale. The closer the score was to one, the less important the value was. Conversely, the closer the score was to seven, the more important the value was.

\section{Data analysis}

Data were analyzed by means of a confirmatory factor analysis (CFA). This technique makes it possible to test the factorial structures of measurement scales and simultaneously to examine the relationships between several either observed or latent variables. The AMOS software (SPSS - Statistical Package for Social Sciences, version 19) was used to carry out the analysis. The estimation method used was the maximum likelihood (ML). The saturations of the post-materialist value system $(\gamma)$ on the social well-being, individual well-being and professional well-being value subsystems were tested, as well as the factor loadings of the items for each value system $(\lambda)$, since they should be statistically significant. The following indicators were used to test the goodnessof-fit of the scale: chi-square $\left(\chi^{2}\right)$, relative chi-square $\left(\chi^{2}\right.$ $/ d f$ ), CFI (comparative fit index), GFI (goodness-of-fit index), TLI (Tucker-Lewis index), and RMSEA (root mean square error of approximation). The chi-square test is a significance test that shows how the model fits the data. This metric indicates good adjustment when the $\chi^{2}$ value is non-significant $(p \geq .05)$.

However, the chi-square value depends on the sample size, which may lead to inappropriate rejection of models that fit the data (Garson 2012). The relative chi-square 
indicator is an alternative to the chi-square since it is less dependent on the sample size. Values up to 3 are acceptable (Iacobucci 2010). For the other indices (CFI, GFI and TLI) values closer to 1 indicate a better fit and values between .80 and .90 indicate acceptable adjustment (Garson 2012). Finally, for the RMSEA with a confidence interval (CI) of $90 \%$, values up to .06 indicate a satisfactory adjustment and values up to .10 are considered to be acceptable (Byrne 2010).

To test the structure hypothesis, we used multidimensional scaling (MDS), proceeding from a similarity matrix between the 24 values, and used the squared Euclidean distances (ALSCAL algorithm). The raw scores were transformed into $\mathrm{Z}$ scores before creating the distance matrix. The analyses were performed at the ordinal level fixing the extraction of two dimensions. Stress and RSQ (squared correlation coefficient) values were used to evaluate the model fit. These indices covary inversely, which means that the dimensionality of the space is evaluated by a decrease in the value of the stress and a corresponding increase in RSQ. A stress value closer to 0 and a RSQ value closer to 1 indicate a better model fit, but values up to .20 and equal to or greater than .60, respectively, are acceptable (Schiffman et al. 1981).

\section{Procedure}

Initially, contact with secondary schools was made by means of a letter soliciting the authorization to administer the questionnaires to students. After obtaining authorization, contact was made with the teachers so that the questionnaires could be filled in during class hours. Participants were assured of the confidentiality of their responses and signed an informed consent form. The research project was approved by the ethics committee of the Faculty of Psychology and Educational Sciences (FPCEUP) of the University of Porto (Portugal).

\section{Results}

With regard to the factorial adjustment (see Fig. 1), the results suggested that the proposed model is suitable to represent the degree of adherence to the values by the Brazilian adolescents, $\chi^{2}(243)=658.62, p<.001, \chi^{2} / d f=$ 2.71, GFI $=.89, C F I=.88, T L I=.86$, RMSEA $($ CI $95 \%)=.06$ [.05-.06]. The results also showed that the post-materialist system is adequately represented by the subsystems of social well-being $(\gamma=.79)$, individual well-being $(\gamma=.86)$ and professional well-being $(\gamma=.94)$. The subsystem of social well-being covers the values of equality, liberty, fraternity and social justice $(\lambda=.40$ to .72$)$.

As proposed, the values of self-realization, joy, comfort and love were concentrated in the individual well-being subsystem $(\lambda=.41$ to .59$)$, and the subsystem of professional well-being included the values of professional realization, dedication to work, competence and responsibility $(\lambda=.53$ to .66$)$. The hedonistic system included the values of pleasure, sexuality, sensuality and excitement $(\lambda=.39$ to .83$)$, and the materialist system contained the values of authority, richness, profit and status $(\lambda=.37$ to .73). Finally, the values of religiosity, fear of God, salvation and obedience to God's laws composed the religious system $(\lambda=.62$ to .85$)$. All factor loadings were statistically significant $(p<.001)$. The internal consistency indices of post-materialist, hedonistic, materialist and religious systems were satisfactory (Cronbach's alpha $=.80, .80, .67$ and .78 , respectively).

The multidimensional scaling analysis showed good fit indices $(R S Q=.89$, Stress $=.16)$ for the two-dimensional solution. The four value systems emerged separately in the space. The materialist values clustered in the lower left quadrant, the post-materialist values in the upper right quadrant, the hedonistic values in the upper left quadrant and religious values in the lower right quadrant. Figure 2(a) shows the graphic representation of the values for the sample of Brazilian teenagers.

For the Portuguese sample, we also found good adjustment of the proposed model, $\chi^{2}(243)=541.31, p<.001, \chi^{2} /$ $d f=2.23, \mathrm{GFI}=.85, \mathrm{CFI}=.82$, TLI $=.80$, RMSEA $(\mathrm{CI} 95 \%)$ $=.07[.06-.08]$. Figure 3 shows that the post-materialist system is well represented by the subsystems of social wellbeing $(\gamma=.71)$, individual well-being $(\gamma=.98)$, and professional well-being $(\gamma=.82)$.

The subsystem of social well-being was adequately represented by the values of liberty, equality, fraternity and social justice $(\lambda=.38$ to .64$)$. The subsystem of individual well-being was also adequately represented by the values of self-realization, joy, comfort and love $(\lambda=.34$ to .50$)$. The values of professional realization, dedication to work, competence and responsibility concentrated accurately in the professional well-being subsystem $(\lambda=.49$ to .76$)$. The hedonistic system organized the values of pleasure, sexuality, sensuality and excitement $(\lambda=.65$ to .80$)$. The values of authority, richness, profit and status adequately represented the materialist system $(\lambda=.35$ to .61$)$. The religious system was also properly formed by the values of religiosity, fear of God, salvation and obedience to God's laws $(\lambda=.71$ to .90$)$. All factor loadings were statistically significant $(p<.001)$. With regard to reliability, the post-materialist, hedonistic, materialist and religious systems had satisfactory internal consistency indices (Cronbach's alpha $=.77, .83, .60$ and .84, respectively).

The multidimensional scaling analysis showed satisfactory fit indices for the two-dimensional solution, RSQ $=.71$, Stress $=.23$. The four systems emerged separately: the materialist system was located in the upper left quadrant and the post-materialist in the upper right quadrant, the hedonistic system emerged in the lower left quadrant and the religious in the lower right quadrant. It should be noted that 


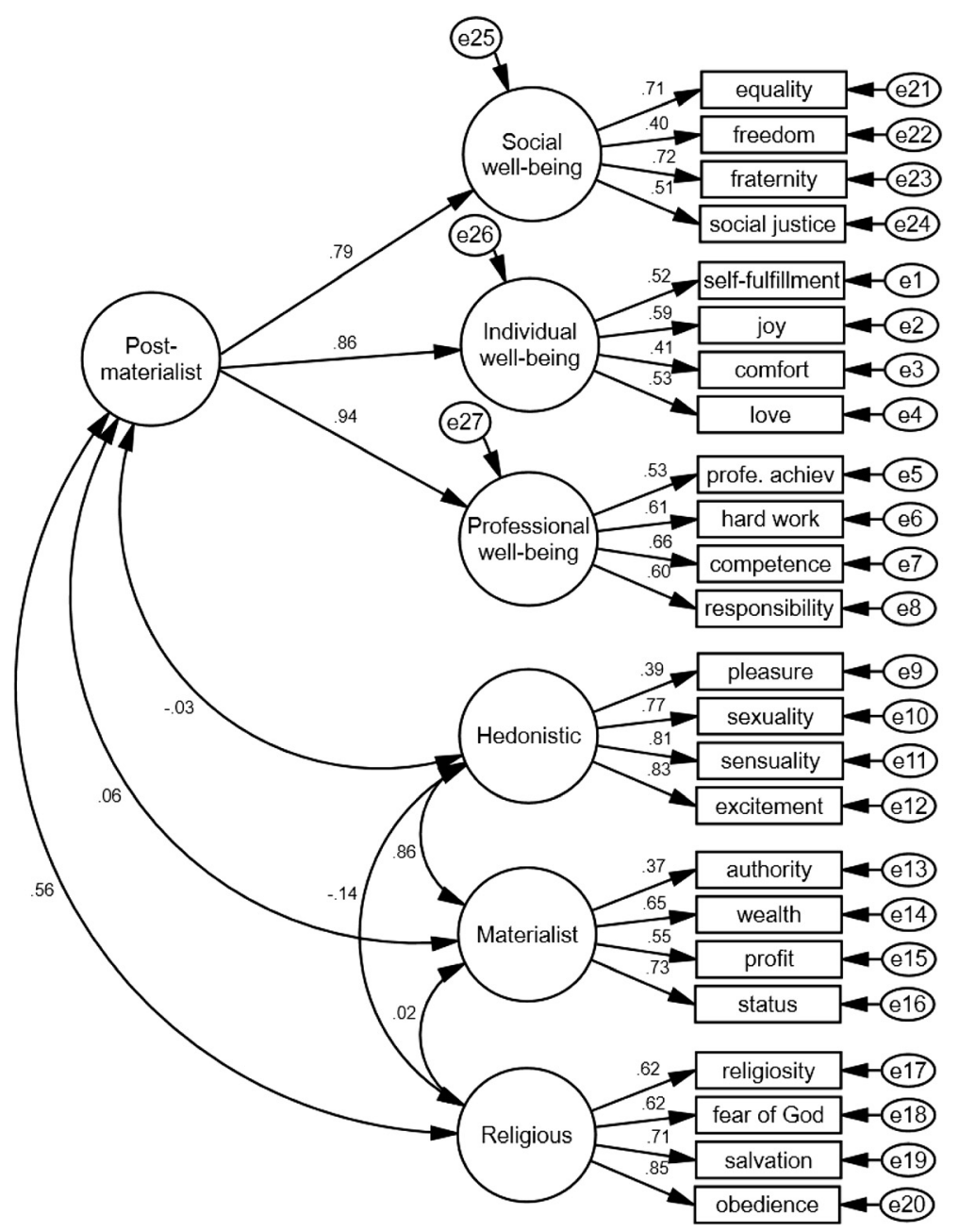

Fig. 1 Factor structure of the Psychosocial Values Questionnaire (Brazil)

the values of love, excitement and authority emerged out of the quadrants of their systems: the value of love emerged in the hedonistic system quadrant, excitement in the quadrant of the materialist system, and the value of authority in the quadrant of the religious system. Figure 2(b) shows the plot of values for the Portuguese adolescents.

Finally, we tested the invariance of measurement between countries. First, the configurational invariance, in which the items were defined for each factor and the factor loadings and covariance were freely estimated, was tested. The adjustment indices obtained were as follows: $\chi^{2}(486)=1.200, p<.01, \mathrm{GFI}=.89, \mathrm{CFI}=.86$, RMSEA $(\mathrm{CI}$ $95 \%)=.045[.042-.048]$. Then the metric invariance was tested, with the factor loadings and covariance being fixed for the two samples. The adjustment indices obtained were as follows: $\chi^{2}(510)=1.319, p<.01$, GFI $=.87, \mathrm{CFI}=.84$, RMSEA (CI $95 \%)=.047$ [.044-.050]. In both tests, the proposed model showed good indices of RMSEA, and the GFI and the CFI were close to the cutoff point of .90. To test the hypothesis of the invariance of the factor structure across countries, the difference between the CFI $(\triangle C F I)$ of the free and restricted models was computed, as suggested by Cheung and Rensvold (2002), adopting a cutoff value of .01 to accept the possibility of invariance. The $\triangle$ CFI was .02 , i.e., higher than, but still close to, the suggested cutoff point.

\section{Discussion}

The objective of this study was to adapt and validate the PVQ-24 to assess values in a sample of Brazilian and Portuguese teenagers, and test the cross-cultural validity of the content and structure hypotheses of the societal approach to values. The results provide satisfactory evidence that the PVQ-24 has construct validity and reliability and can be applied to assess teenagers' values in Brazil and Portugal. These findings suggest that the proposed factor structure, although it is not absolutely invariant, presents minimal differences across countries.

The confirmatory factor analysis showed the adjustment of the proposed factor solution, composed of four systems 


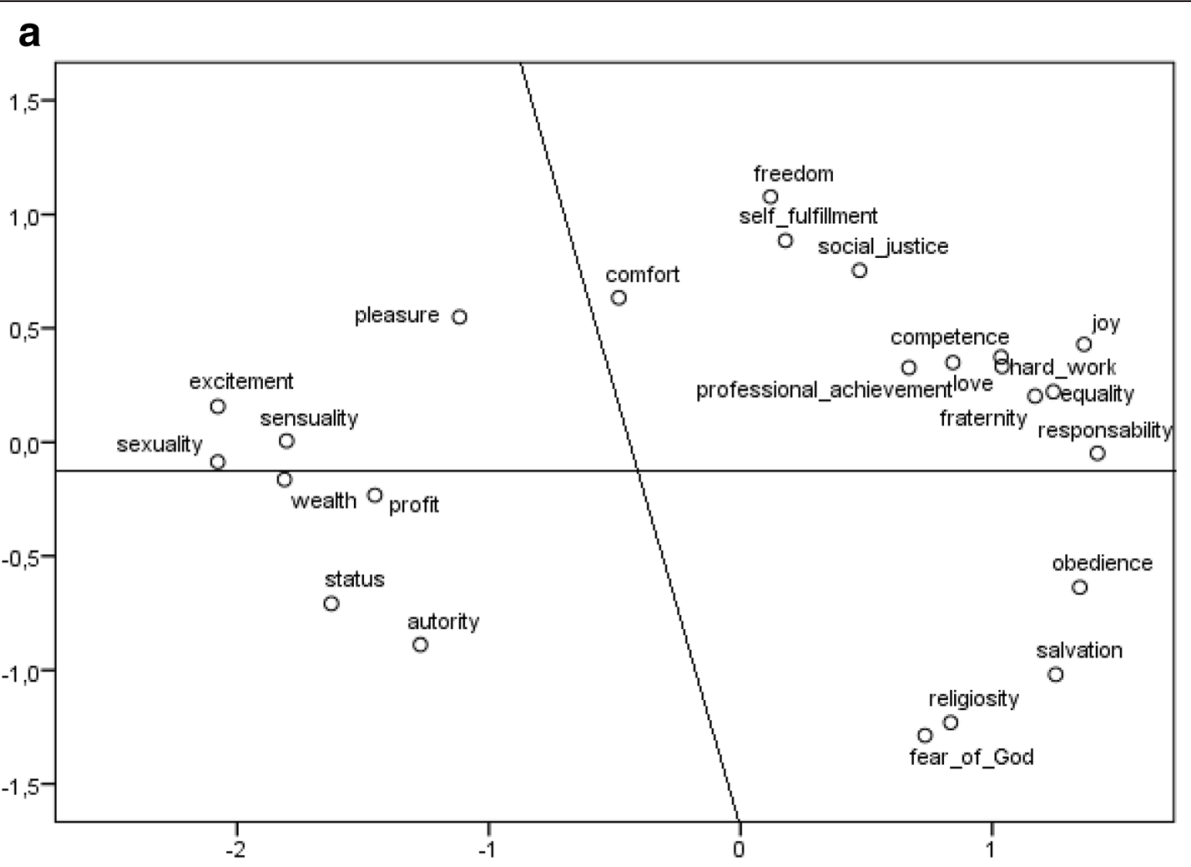

b

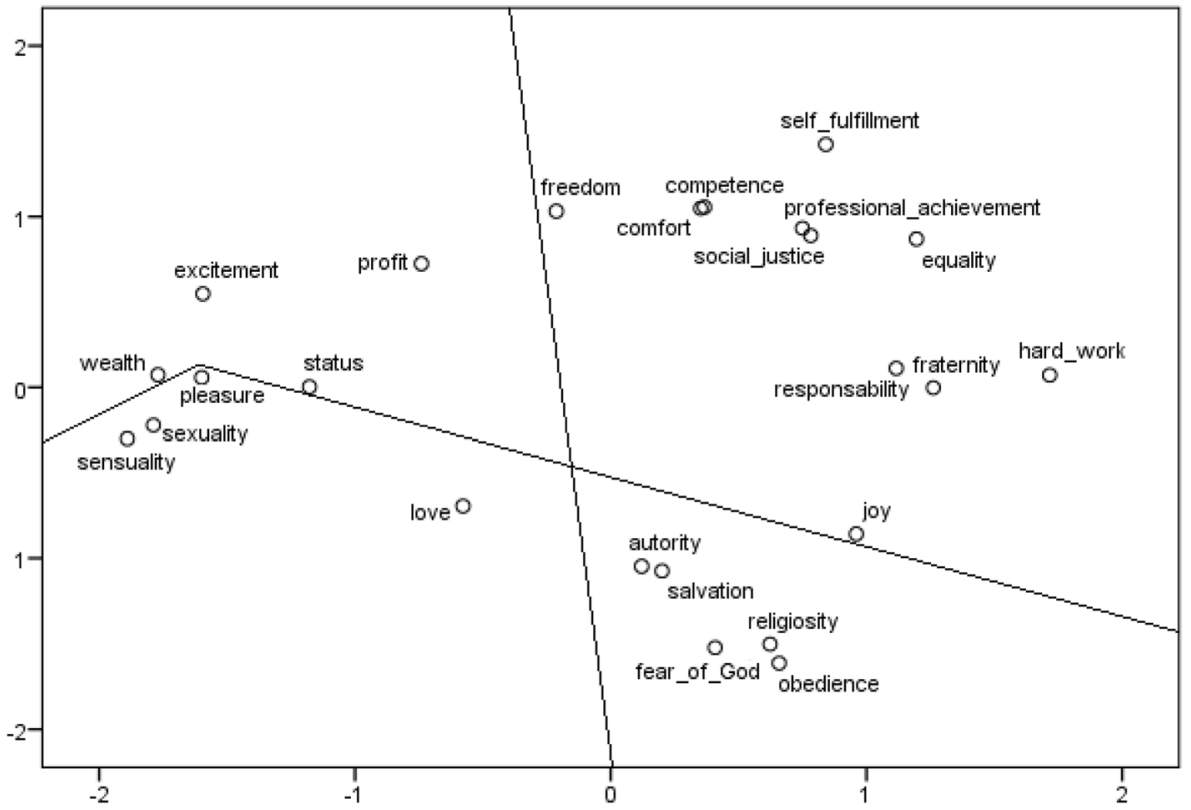

Fig. 2 Value structure in Brazilian (a) and Portuguese (b) teenagers samples

(materialist, post-materialist, religious and hedonistic), with the post-materialist system divided into three sub-systems (social well-being, individual well-being and professional well-being). The items presented significant factor loadings, ranging between .37 and .85 , for the Brazilian sample and between .34 and .90 for the Portuguese sample. Postmaterialist, hedonistic and religious systems showed alphas above .70 in both samples, while only the materialist system showed alphas between .60 and .70 .
These results are consistent with previous investigations using the PVQ-24 (Pereira et al. 2004a, b, c; Pereira et al. 2005). It is worth mentioning that the internal consistency of the PVQ-24 are close to the indices reported in other studies with human values, such as those performed with the Portrait Values Questionnaire or Schwartz Values Survey (Schwartz 1992; Schwartz et al. 2001). Hence, low internal consistency is not only a limitation of this study, since human values tend to have low internal consistency 


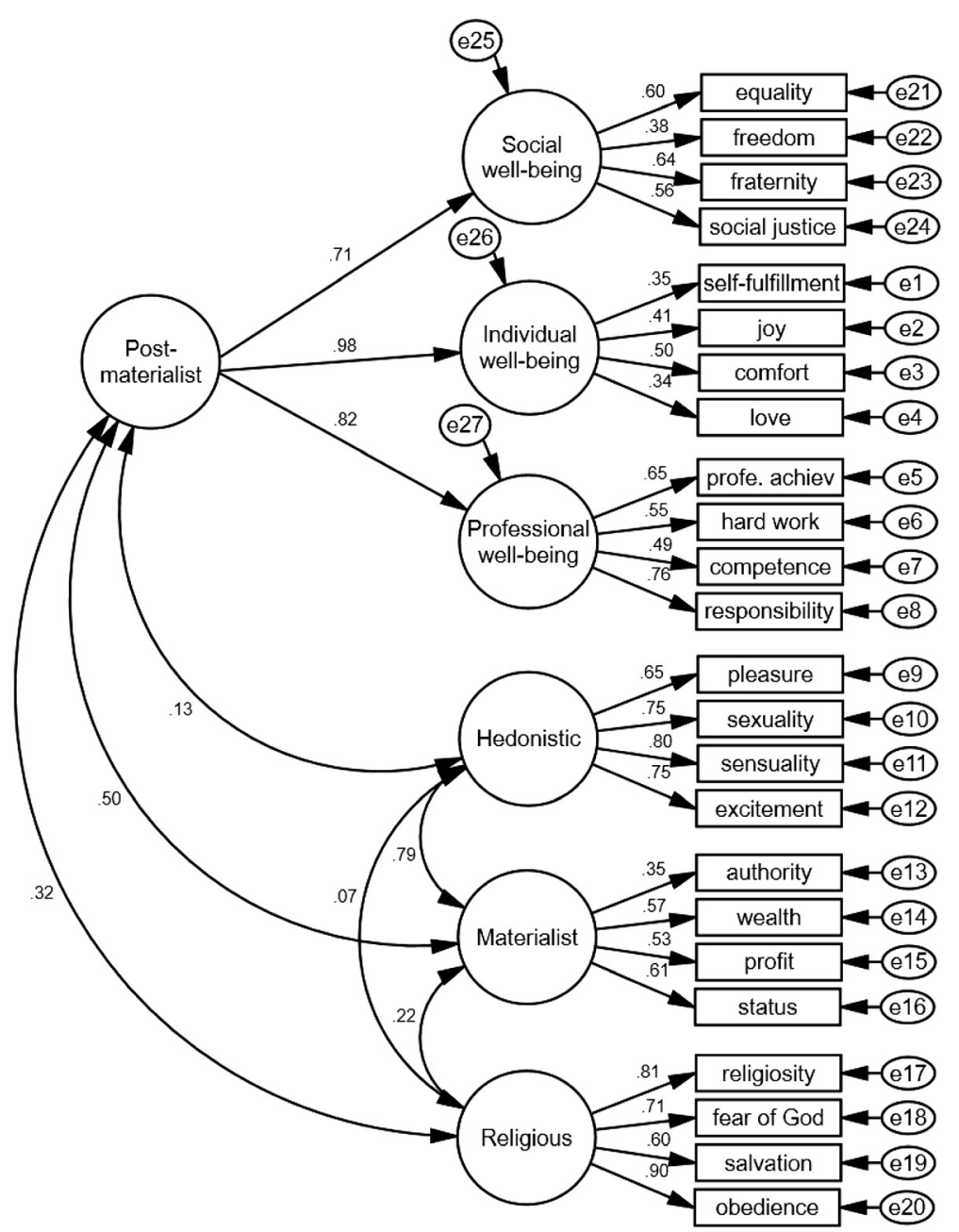

Fig. 3 Factor structure of the Psychosocial Values Questionnaire (Portugal)

indices due to low variability in responses (Rodriguez and Maeda 2006).

Taken together, the results obtained by the CFA and MDS provide empirical evidence that allow accepting the content and structure hypotheses of the societal approach to values, as well as the proposed compatibility between the value systems. The content hypothesis was confirmed by the AFC that demonstrated the appropriateness of the four systems proposed by the societal approach to values: hedonist, religious, materialist and post-materialist. The last system also includes three subsystems: social well-being, individual well-being and professional well-being. All items have significant factor loadings, greater than .30 for both samples. These results corroborate those found by Pereira et al. (2004a, b, c).

The structure hypothesis proposes the existence of two dimensions, one formed by the materialist and postmaterialist systems and the other by religious and hedonist systems. The results obtained by MDS demonstrate that these systems are organized in two dimensions, as proposed by the theory. According to Pereira et al. (2004a, b, c), religious and hedonist systems represent opposite ideologies and interests (Schwartz 1996). Similarly, opposition between the materialist and post-materialist systems is likely because they emerged in different socioeconomic contexts (Inglehart 1989). However, the interpretation of the opposition between the value systems has to be pondered, taking into account the positive correlation between values (Pereira et al. 2005).

The bidimensional model is most prominent in the Brazilian sample, since in the Portuguese sample the values of love and authority emerged in different quadrants, outside their proposed systems. The value of love emerged near the center of the space, still in the hedonistic quadrant system, while the value of excitement in life emerged in the quadrant of the materialist system and the value of authority emerged in the quadrant of the religious system. Although the value systems have different contents, it is likely that these differences are not discrete, but continuous (Schwartz 1992). Pereira et al. (2005), correlating 
the systems proposed by the societal approach with the motivational types of Schwartz (1992), found significant correlations between the religious system and conservation values. In this sense, the authority value has similar content with the conformity values of Schwartz (1992), which can help understand the results observed in the Portuguese sample.

The covariances between the systems were mostly positive, except those observed between religious and hedonist systems in the Brazilian sample. Taken together, the covariance between the systems corroborate the hypothesis of compatibility, because the value systems are structured in function of their compatibility and not based on conflict, as proposed by Schwartz (1992). According to Pereira et al. (2005), these correlations show that the conception of conflict between values (Schwartz 1996) contradicts the existence of the social desirability of axiological systems. However, conflicts can exist between individual and social motivations, because values are not cognitive representations of individual interest and motivations. That is, values have little to do with needs, since they are mainly related to ideas about how society should be organized (Deschamps and Devos 1993). Thus, the division between individual and social values is unreliable, because all the values are social to the extent that they are produced in social interactions (Beattie, 1980; Lima 1997) and are widely shared by individuals (Maio and Olson, 1998).

\section{Conclusions}

In conclusion, we can affirm that the PVQ-24 proved to be a valid and reliable measure to assess the values of Brazilian and Portuguese adolescents and the content and structure hypotheses of the societal approach to values were confirmed, in whole or in part, in both samples. It is worth mentioning that the value system of adolescents tend to be less differentiated compared to adults, since teenagers' motivational and valorative structures are not fully stabilized (Schwartz, 2001). This is a possible explanation for the limitations observed in this study, particularly with regard to the fact that the value structure of the Portuguese sample was not as clear as that observed in the Brazilian sample. Although the average age was similar in both samples, the Portuguese group had a higher standard deviation, suggesting less homogeneity. In this sense, further studies in other cultures are needed to test the hypotheses proposed by the societal approach to values, as well as studies evaluating the stability of the factor structure of the PVQ24 in other cultural contexts.

\section{Competing interests}

The authors declare that they have no competing interests.

\section{Authors' contributions}

SL collaborated in drafting the background, data analysis and discussion of the results, and was responsible for data collection as well. GP contributed by critically reviewing the background, data analysis and discussion of results. TJSL collaborated in drafting the background, data analysis and discussion of results. LECS contributed in the data analysis, description of results, preparation of tables and figures and text revision. CRP contributed by critically reviewing the background, data analysis, discussion of results and final revision of the manuscript. All authors read and approved the final manuscript.

\section{Acknowledgements}

This research was supported by the Erasmus Mundus External Cooperation Window Program (Project MUNDUS17 - coordinated by the University of Porto).

\section{Author details}

${ }^{1}$ Pontifical Catholic University of Rio de Janeiro, Rio de Janeiro, Brazil. ${ }^{2}$ University of Porto, Porto, Portugal. ${ }^{3}$ University of Fortaleza, Fortaleza, Brazil. ${ }^{4}$ Federal University of Paraíba, João Pessoa, Brazil.

Received: 18 March 2016 Accepted: 7 April 2016

Published online: 18 April 2016

\section{References}

Barros TS, Torres ARR, Pereira C. Autoritarismo e adesão a sistemas de valores psicossociais. Psico-USF. 2009;14:47-57.

Bean C, Papadakis E. Polarized priorities or flexible alternatives? Dimensionality in Inglehart's materialism-posmaterialism scale. Int J Public Opin Res. 1994;6:264-97.

Beattie J. Introdução à antropologia social. São Paulo: Companhia Editora Nacional; 1980.

Berger PL, Luckmann T. A construção social da realidade. Petrópolis, RJ: Vozes; 1973.

Blakemore SJ, Mills KL. Is adolescence a sensitive period for sociocultural processing? Annu Rev Psychol. 2014;65:187-207.

Byrne BM. Structural equation modeling with AMOS, (2nd ed.). New York: Routledge; 2010.

Cheung GW, Rensvold RB. Evaluating goodness-of-fit indexes for testing measurement invariance. Struct Equ Modeling. 2002;9:233-55.

Costa JB. Visões sociais de democracia: Um estudo psicossociológico dos significados da democracia, Tese de Doutorado não-publicada, Curso de Pósgraduação em Psicologia Social, Pontifícia Universidade Católica de São Paulo. SP: São Paulo; 2000.

Deschamps J, Devos T. Valeurs, cultures et changement. Intercultures. 1993;1:17-28.

Doise W. L'explicacation en psychologie sociale. Paris: PUF; 1982.

Estramiana JLA, Pereira CR, Monter MR, Zlobina A. Valores Sociais. In: Camino L, Torres A, Lima M, Pereira M, editors. Psicologia Social. Brasília: TechnoPolitik; 2014. p. 309-54

Fernandes S, Costa J, Camino L, Mendoza R. Valores psicossociais e orientação à dominância social: Um estudo acerca do preconceito. Psicologia: Reflexão e Crítica. 2007;20:490-8.

Garson GD. Factor Analysis. Asheboro: Statistical Associates Publishing; 2012.

Gouveia W, Milfont TL, Guerra VM. Functional theory of human values: Testing its content and structure hypotheses. Personal Individ Differ. 2014;60:41-7. doi:10.1016/j.paid.2013.12.012.

Hofstede G. Culture's Consequences: International Differences in Work-Related Values. Beverly Hills, CA: Sage; 1980.

lacobucci D. Structural equations modeling: Fit indices, sample size, and advanced topics. J Consum Psychol. 2010;20:90-8. doi:10.1016/j.jcps.2009.09.003.

Inglehart R. The silent revolution. Princeton: Princeton University; 1977.

Inglehart R. Culture shift in advanced industrial society. Princeton: Princeton Academic Press; 1989.

Inglehart R. El cambio cultural en las sociedades industriales avanzadas. Madrid: Siglo XXl; 1991.

Inglehart R. Modernización y post-modernización: La cambiante relación entre el desarrollo econômico, cambio cultural y político. In: Nícolas JD, Inglehart R, editors. Tendencias mundiales de cambio en los valores sociales y políticos. Madrid: Fundesco; 1994. p. 157-70.

Kidd Q, Lee AR. Postmaterialist values and the environment: A critique and reappraisal. Soc Sci Q. 1997;78:1-15.

Kluckhohn C. Values and value-orientations in the theory of action: An exploration in definition and classification. In: Parsons T, Shils E, editors. Toward a general theory of action. Cambridge: Harvard University Press; 1951. p. 388-433.

Lima, M. E. (1997). Valores, participação política, atitudes face a democracia e ao autoritarismo: Uma análise da socialização política dos universitários da 
Paraíba. Dissertação de Mestrado não-publicada, Universidade Federal da Paraíba, João Pessoa, PB.

Lins SLB, Lima-Nunes A, Camino L. O papel dos valores sociais e variáveis psicossociais no preconceito racial brasileiro. Psicologia \& Sociedade. 2014;26:95-105. doi:10.1590/50102-71822014000100011.

Maio GR, Olson JM, Allen L, Bernard M. Addressing discrepancies between values and behavior: The motivating effect of reasons. J Exp Soc Psychol. 2001;37:104-17. doi:10.1006/jesp.2000.1436.

Maio GR, Olson JM. Values as truisms: evidence and implications. Journal of Personality and Social Psychology. 1998;74:294-311.

Pereira C, Camino L. Proposta de um modelo psicossociológico para o estudo das atitudes políticas de estudantes universitários: Uma análise em termos de valores materialistas e pós-materialistas. In: Souza MFV, editor. Iniciados. João Pessoa: Editora Universitária; 1999. p. 427-40.

Pereira C, Lima ME, Camino L. A prática política: Uma análise psicossociológica em termos de valores e inserção social. In: Silva MJL, editor. Iniciados. João Pessoa: Editora Universitária; 1997. p. 199-235.

Pereira C, Camino L, Da Costa J, Lima ME, Lhullier L, Sandoval S. Sistemas de valores e atitudes democráticas de estudantes universitários do Sul do Brasil. Estudos. 2001;28:639-71.

Pereira C, Camino L, Costa JB. Análise fatorial confirmatória do Questionário de Valores Psicossociais - QVP-24. Estud Psicol. 2004a;9:505-12.

Pereira C, Ribeiro ARC, Cardoso SJ. Envolvimento nos direitos humanos e sistemas de valores. Psicologia em Estudo. 2004b:9:55-65.

Pereira C, Torres ARR, Barros TS. Sistemas de valores e atitudes democráticas de estudantes universitários. Psicologia: Teoria e Pesquisa. 2004c;20:1-10. doi:10.1590/S0102-37722004000100002.

Pereira C, Camino L, Costa JB. Um estudo sobre a integração dos níveis de análise dos sistemas de valores. Psicologia: Reflexão e Crítica. 2005;18:16-25.

Rodriguez MC, Maeda Y. Meta-analysis of coefficient alpha. Psychol Methods. 2006;11:306-32. doi:10.1037/1082-989X.11.3.306.

Rokeach M. The nature of human values. New York: Free Press; 1973.

Santos C, Fernandes D. A socialização de consumo e a formação do materialismo entre os adolescentes. RAM-Revista de Administração Mackenzie. 2011;12(1):169-203.

Schiffman SS, Reynolds ML, Young FW. Introduction to Multidimensional Scaling. New York: Academic; 1981.

Schwartz SH. Universal in the content and structure of values: Theoretical advances and empirical tests in 20 countries. In: Zanna MP, editor. Advanced in experimental social psychology. New York, NY: Academic; 1992. p. 1-65.

Schwartz SH. Value priorities and behavior: Applying a theory of integrated value systems. In: Seligman C, Olson JM, Zanna MP, editors. The Ontario Symposium: The psychology of values vol. 8. Hillsdale: Lawrence Erlbaum; 1996. p. 1-24.

Schwartz SH. A theory of cultural value orientations: Explication and applications. Comp Sociol. 2006;5:136-82

Schwartz SH, Bilsky W. Toward a universal psychological structure of human values. J Pers Soc Psychol. 1987;53:550-62.

Schwartz SH, Cieciuch J, Vecchionem M, Davidov E, Fischer R, Beierlein C, et al. Refining the Theory of Basic Individual Values. Pers Process Individ Differ. 2012:103:663-8. doi:10.1037/a0029393.

Schwartz SH, Melech G, Lehmann A, Burgess S, Harris M, Owens V. Extending the cross-cultural validity of the theory of basic human values with a different method of measurement. Journal of Cross-Cultural Psychology. 2001;32:519-42.

Torres ARR. Uma análise psicossocial da identificação partidária: O caso dos estudantes da UFPb nas eleições de 1988, 1989 e 1990, Dissertação de Mestrado não-publicada. João Pessoa, PB: Universidade Federal da Paraíba; 1992.

Torres ARR, Pereira C, Guimarães J, Albernaz M, Vieira S, Barros T. Valores e psicologia social: Modelos de análise. Estudos. 2001:28:539-59.

Williams RM. Change and stability in values and value systems: A sociological perspective. In: Rokeach M, editor. Understanding human values: Individual and societal. New York: Free Press; 1979. p. 15-46.

\section{Submit your manuscript to a SpringerOpen ${ }^{\circ}$ journal and benefit from:}

- Convenient online submission

- Rigorous peer review

- Immediate publication on acceptance

- Open access: articles freely available online

- High visibility within the field

- Retaining the copyright to your article

Submit your next manuscript at $\gg$ springeropen.com 